University of Nebraska - Lincoln

DigitalCommons@University of Nebraska - Lincoln

Sociology Department, Faculty Publications

Sociology, Department of

3-2006

\title{
Pathways In and Out of Substance Use Among Homeless- Emerging Adults
}

\author{
Kimberly A. Tyler \\ University of Nebraska-Lincoln, kim@ktresearch.net \\ Katherine Johnson \\ University of Nebraska-Lincoln
}

Follow this and additional works at: https://digitalcommons.unl.edu/sociologyfacpub

Part of the Sociology Commons

Tyler, Kimberly A. and Johnson, Katherine, "Pathways In and Out of Substance Use Among HomelessEmerging Adults" (2006). Sociology Department, Faculty Publications. 54.

https://digitalcommons.unl.edu/sociologyfacpub/54

This Article is brought to you for free and open access by the Sociology, Department of at DigitalCommons@University of Nebraska - Lincoln. It has been accepted for inclusion in Sociology Department, Faculty Publications by an authorized administrator of DigitalCommons@University of Nebraska - Lincoln. 


\title{
Pathways In and Out of Substance Use Among Homeless-Emerging Adults
}

\author{
Kimberly A. Tyler \& Katherine A. Johnson \\ University of Nebraska-Lincoln
}

\begin{abstract}
Although high rates of alcohol and drug use have been found among homeless young people, less is known about who is responsible for their initiation, the reasons for their continued use, and why some individuals eventually transition out of using whereas others do not. Based on qualitative interviews with 40 homeless individuals 19 to 21 years of age in the Midwest, results revealed that the majority of respondents were initiated into substance use by friends and acquaintances, although family also played a significant role. Almost one half of respondents reported using substances to cope with early family abuse, stress, and life on the streets. Additionally, the majority indicated that they had no intentions of quitting. Substance misuse that is left untreated may lead to chemical dependency among homeless emerging adults and may contribute to long-term homelessness.
\end{abstract}

Keywords: alcohol use, illicit drug use, homeless

Substance use has been found to be a common experience among homeless young people. Prevalence rates for lifetime, past 3 months, and current alcohol usage are consistently high (Kral, Molner, Booth, \& Watters, 1997; MacLean, Paradise, \& Cauce, 1999; Martinez et al., 1998). Frequent use of illicit drugs among homeless young people is also common, with estimates of crack or cocaine usage between 16\% and 65\% (Bailey, Camlin, \& Ennett, 1998; Baron, 1999; Kral et al., 1997). When compared to those who are housed, runaways have been found to exhibit much higher rates of substance use (Fors \& Rojek, 1991; Rosenthal, Moore, \& Buzwell, 1994). Fors and Rojek (1991), for example, found drug and alco-

This research was funded by a University of Nebraska-Lincoln Faculty Seed Grant awarded to the first author and by the National Institute of Mental Health (MH 57110).

Correspondence - Dr. Kimberly A. Tyler, University of Nebraska-Lincoln, Department of Sociology, 717 Oldfather Hall, Lincoln, NE, 68588-0324. Tel 402 472-6073; Fax 402 472-6070; Email kim@ktresearch.net 
hol use and abuse to be two to three times more prevalent among homeless young people than among those attending school.

Although high rates of alcohol and drug use exist among homeless young people, less is known about their initiation into substance use and the role that family plays in this process. According to Baron (1999), homeless young people often have family histories that promote substance use initially, but their risk of substance use is further exacerbated by their associations with drug-using peers as well as their street experiences. Given the social context of young homeless people's lives prior to their leaving home (e.g., parental substance misuse, family abuse; Janus, McCormack, Burgess, \& Hartman, 1987; Tyler \& Cauce, 2002; Whitbeck \& Hoyt, 1999) and the cultural context of street life (e.g., trying to find a place to sleep, high rates of victimization; Tyler, Whitbeck, Hoyt, \& Cauce, 2004), drugs and alcohol may be used by homeless-emerging adults as a way to cope with their past and present situations.

Although there is an abundance of research on homeless older adults and a growing body of research on homeless adolescents, very little research to date addresses the population of homeless-emerging adults (i.e., 18 to 25 years of age; Arnett, 2000, 2004); therefore, we know virtually nothing about them as a group, including the process surrounding initiation into and out of substance use. Additionally, national statistics reveal that substance use is higher during the emerging adult years (ages 18 to 25) than at any other age period (Substance Abuse and Mental Health Services Administration, 2003). Moreover, emerging adulthood is seen as a time of great instability (numerous life changes in intimate partners, jobs, residence), which may lead to increases in substance use via anxiety, sadness, and depression (Arnett, in press, 2004). If instability is a risk factor for substance use, homeless-emerging adults are especially at high risk given the inordinate number of transitions they experience prior to leaving home (Whitbeck \& Hoyt, 1999) as well as once they are on their own (Tyler, in press). Additionally, from a developmental perspective, current substance users who began using alcohol and drugs at an early age are likely to be at greater risk for developing chemical dependency problems. Finally, it is important that we learn more about homeless-emerging adults because it is during this critical transition period that work patterns are established and marital relationships are formed. Failure to successfully establish one's self as a young adult may have life-long repercussions including becoming part of the older adult homeless population.

The purpose of this article is to address how respondents first came to use substances, reasons for their continued use, and why some of them eventually transitioned out of using whereas others did not, based on in depth qualitative interviews with 40 homeless-emerging adults. In addi- 
tion to providing much needed information on an understudied population, the results of this study may also be helpful in developing programs for prevention and early intervention among such groups.

\section{Literature Review}

Lifetime substance use rates as high as $97 \%$ have been reported among homeless young people (Kral et al., 1997; Martinez et al., 1998). Not only do these young homeless people report high prevalence rates, but research finds that many meet diagnostic criteria for alcohol or drug use dependency (Kipke, Montgomery, Simon, Unger, \& Johnson, 1997). According to Kipke and associates (1997), Diagnostic and Statistical Manual of Mental Disorders-III criteria for either drug or alcohol-abuse disorder was met by $66 \%$ of their sample. Furthermore, according to Bailey and associates (1998), many homeless young people are comorbid and meet diagnostic criteria for both drug and alcohol dependency according to Diagnostic and Statistical Manual of Mental Disorders-IV criteria; Kipke and associates (1997) concur and found 31\% of their sample to be comorbid. Warheit and Biafora (1991) reported that homelessemerging adults are 4.5 times more likely to have a diagnosis of alcohol dependency and 8 times more likely to have a diagnosis of drug dependency than their housed counterparts (Warheit \& Biafora, 1991). Moreover, young people on the street view drug involvement as far less serious than young people who are enrolled in school. According to Fors and Rojek (1991), many runaways have a pro-drug ethos and do not view these substances as being harmful. Given the situational context of street life, it is possible that drugs are viewed as normative within certain groups.

Although studies exist on the prevalence of substance use, there is a paucity of research that addresses the process of initiation into and out of alcohol and drug use among homeless-emerging adults. Kipke, Unger, Palmer, and Edgington (1996) addressed the initiation of homeless young people into substance usage and found that the majority were introduced to illicit drugs by a friend $(47 \%)$ or family member $(25 \%)$. Little is known, however, about the overall process in terms of family influence, peer influence, street norms, and so on. Kipke and colleagues (1996) have called for more research addressing these important issues.

Parental substance abuse has been found to be a common experience among homeless young people. According to Fors and Rojek (1991) a large portion of their sample of homeless young people were raised in family environments where rates of substance use among parental fig- 
ures were exceedingly high. Similarly, Ginzler, Cochran, Domenech-Rodriguez, Cauce, and Whitbeck (2003) found that a large number of homeless young people were raised in families where either their father $(55 \%)$ or their mother $(46 \%)$ had problems with substance use. According to Fors and Rojek (1991), growing up in substance-abusing families may predispose young people to become substance users themselves. Very few details exist, however, regarding the process of parental involvement, whether it be direct or indirect, on young people's initiation into alcohol and drug use.

Once on the streets, young people's predisposition toward substance use may be exacerbated by involvement with drug-using peers. According to Baron (1999), homeless young people are involved in a street lifestyle that encourages and rewards substance use. Additionally, homeless people's proclivity toward substance use may also be related to lack of resources and lack of quality employment. For example, homeless young people who hold low-paying or poor-quality jobs are more likely to use illicit drugs (Baron, 1999). Furthermore, without the guidance and support of parents, teachers, nondelinquent peers, or the structure that attending school or having a job provides, many homeless young people are left to fend for themselves. Frustration may result and some individuals may subsequently turn to substance use. Once drug use becomes frequent, homeless young people may find it necessary to undertake criminal activities to support their habit (Baron, 1999). Therefore, the cultural context of street life is important for explaining homeless young peoples' continued use of drugs.

Drugs and alcohol have also been found to serve many purposes for young people having to survive on the streets. For example, some researchers contend that methamphetamines allow homeless young people to stay awake for extended periods of time, which lessens their chances of being victimized (Ayerst, 1999; Ginzler et al., 2003). Additionally, some drugs may be used to provide a feeling of warmth, especially during the winter (Ayerst, 1999) and as a method of coping with the stresses of street life (Kidd \& Kral, 2002). These findings suggest that drug use may be viewed as useful and even necessary, given the cultural context of street life, which includes having to survive with limited resources.

\section{Method}

This investigation is based on data obtained from semistructured interviews with 40 homeless-emerging adults as part of a larger longitudinal study. Young people were interviewed in four Midwestern states (Missouri, Iowa, Nebraska, Kansas) by street interviewers who were em- 
ployed full time as survey researchers by the larger longitudinal project. Interviewers worked through the local service agencies to both collect data and serve as referral sources for services requested by homelessemerging adults in crisis. This created greater access to the desired population and minimized the impression of an intrusive researcher. Interviewers were instructed to approach shelter residents and locate eligible respondents in areas of the cities where homeless young people congregate. Interviews were conducted in shelter interview rooms, quiet corners of restaurants, and libraries. All interviewers had over 2 years of experience interviewing and interacting with homeless young people and were very familiar with local street cultures (e.g., knowing where young homeless people congregate and the kinds of services available to them). Study eligibility required young people to be between 19 and 21 years of age and homeless. The definition of homeless mandated that the emerging adult currently resided in a shelter or on the street or was temporarily doubling up with friends because they had run away, had been pushed out, or had drifted out of their family of origin. Study procedures were explained and informed consent was obtained from all respondents. Sample characteristics are displayed in Table 1.

\section{Coding and Theme Construction}

All interviews were audio taped and lasted 1 to $1-1 / 2$ hours on average. Participants were asked a series of open-ended questions, which focused on their family background and experiences on the street, including the use of alcohol and drugs (see Appendix A for topics and questions). Each interview was transcribed verbatim. To preserve confidentiality, all names of respondents have been changed. Respondents were paid \$25 for the interview.

The goal of this article was to examine, in depth, substance-use patterns among homeless-emerging adults. Although several theoretical perspectives guided the interviewing and data collection process, the themes that were eventually generated emerged from the words of the respondents rather than from theory. Thus, rather than trying to force young peoples' experiences into preconceived categories, themes were allowed to evolve naturally (Charmaz, 1995). During the process of open coding, each interview was carefully read and all references to alcohol and drugs were highlighted. Three main themes were generated by identifying recurrent topics in the participant's responses: (a) pathways into substance use, (b) reasons for continued use, and (c) pathways out of substance use.

Once these main themes were established and agreed on, each author independently identified specific categories within these general themes and recorded them in the form of a code book in accordance with the 
Table 1: Sample Characteristics

\begin{tabular}{|c|c|c|}
\hline & $N$ & $\%$ \\
\hline \multicolumn{3}{|l|}{ Gender } \\
\hline Male & 16 & 40.0 \\
\hline Female & 24 & 60.0 \\
\hline \multicolumn{3}{|l|}{ Race or ethnicity } \\
\hline White & 27 & 67.5 \\
\hline African American & 8 & 20.0 \\
\hline Hispanic & 1 & 2.5 \\
\hline Biracial or multiracial & 4 & 10.0 \\
\hline \multicolumn{3}{|l|}{ Age $(x=20.17)$} \\
\hline 19 & 19 & 47.5 \\
\hline 20 & 15 & 37.5 \\
\hline 21 & 6 & 15.0 \\
\hline \multicolumn{3}{|l|}{ Education } \\
\hline Completed high school or GED & 15 & 37.5 \\
\hline Currently in high school & 3 & 7.5 \\
\hline Working on GED & 5 & 12.5 \\
\hline Dropped out & 12 & 30.0 \\
\hline Not asked & 5 & 12.5 \\
\hline \multicolumn{3}{|l|}{ Employment } \\
\hline Currently working & 16 & 40.0 \\
\hline Unemployed & 24 & 60.0 \\
\hline \multicolumn{3}{|l|}{ Age on own } \\
\hline Age 14 or younger & 27 & 67.5 \\
\hline Age 15 to 16 & 10 & 25.0 \\
\hline Age 17 to 19 & 3 & 7.5 \\
\hline \multicolumn{3}{|l|}{ Family substance misuse } \\
\hline Yes & 37 & 92.5 \\
\hline No & 3 & 7.5 \\
\hline \multicolumn{3}{|l|}{ Lifetime substance use $\mathrm{e}^{\mathrm{a}}$} \\
\hline Alcohol use & 37 & 92.5 \\
\hline Marijuana use & 34 & 85.0 \\
\hline Illicit drugs use & 21 & 52.5 \\
\hline Light user & 10 & 25.0 \\
\hline Heavy user & 30 & 75.0 \\
\hline
\end{tabular}

a Percentages do not add up to 100 because many youth used more than one type of substance.

methodological techniques proposed by Carey, Morgan, and Oxtoby (1996). Once these initial code books were developed by each author, they were compared and standardized. The authors then each repeated the coding process using the standardized codebook and categorized the highlighted excerpts according to the agreed on criteria. Through this process the researchers were able to independently replicate approx- 
imately $90 \%$ to $95 \%$ of each other's work. All remaining points of contention were resolved by jointly reassessing the original transcripts and discussing any differing interpretations. This process continued until consensus was reached between the authors on all cases. After these themes and categories were identified, the process of focused coding began (Charmaz, 1995), which included searching the coded and categorized excerpts for particularly telling passages and pulling them out for inclusion in the text. More passages were identified than could be included in the manuscript, and thus, agreement was reached by the authors about which quotes were the most exemplary and only these were included (see Appendix B for coding and categorization of data).

\section{Results}

\section{Pathways Into Substance Use}

To appreciate the process of initiation into substance use, it is important to understand more fully the family histories of those sampled. The majority of respondents $(n=36)$ had experienced physical abuse, and 13 had experienced sexual abuse. In addition to abuse, 37 out of the 40 emerging adults reported that a close relative (usually a mother or father) had a substance abuse problem, and 13 individuals said that their mother and father had experienced legal sanctions, often because of selling drugs. Additionally, $85 \%$ of the respondents themselves had used or were currently using marijuana, and almost $53 \%$ had used or were currently using illicit drugs. Three quarters of the sample were heavy users at some point (see Table 1).

The majority of young peoples' initiation into substance use was through four main avenues: (a) family, (b) partner, (c) friends or acquaintances, and (d) the cultural context of street life (see Table 2). Numerous respondents also reported a combination of these avenues into substance use. Nine respondents reported that a family member initially introduced them to drugs. According to Vanessa, her mother heavily abused drugs, and she and her sisters engaged in similar substance-abusing behaviors. When asked whom she engages in substance use with, Vanessa replied, "I don't have any friends, so when I smoke marijuana, it is with my family, like my older sisters."

Stacey was first introduced to marijuana at age 15 by her cousin. She reported frequently witnessing her cousin's marijuana use and wanting to try it herself. Stacey's initiation into substance use was also facilitated by her caretaker. Stacey's 25-year-old aunt, with whom she lived temporarily, smoked marijuana almost daily and allowed Stacey 
Table 2: Frequencies of Pathways Into Substance Use, Reasons for Use, and Pathways Out of Substance Use Among Emerging Adults

\begin{tabular}{lrr}
\hline & $N$ & $\%$ \\
\hline Pathways into substance use & & \\
Family member(s) & 9 & 22.5 \\
Partner & 2 & 5.0 \\
Friend(s) or Acquaintance(s) & 11 & 27.5 \\
The cultural context of street life & 2.5 \\
More than one route of initiation & 1 & 35.0 \\
Unknown & 14 & 7.5 \\
Total & 3 & 100 \\
Reason for use & 40 & \\
Coping (with early abuse, depression, stress, street life) & 18 & 45.0 \\
Social (for recreation, for fun, or to fit in) & 9 & 22.5 \\
Both (coping and social) & 10 & 25.0 \\
Unknown & 3 & 7.5 \\
Total & 40 & 100 \\
Pathways out of substance use & & \\
Precipitating event (e.g., pregnancy, jail) & 12 & 30.0 \\
Unsuccessful transition & 4 & 10.0 \\
No intentions of quitting (light user) & 11 & 27.5 \\
No intentions of quitting (heavy user) & 11 & 27.5 \\
Unknown & 3 & 7.5 \\
Total & 41 & 102.5 \\
\hline
\end{tabular}

a Percentages do not add up to $100 \%$ because one person gave two reasons (i.e., one for alcohol and one for illicit drugs).

to smoke marijuana with her and her friend. Although Stacey's cousin initially got her started, her aunt also appears to be instrumental in Stacey's substance use.

Katie also grew up in a social environment that was conducive to drug use. Katie was 14 years old when she first started smoking marijuana, and when asked where she learned how to use drugs, she replied, "From my mother." Similarly, Tara grew up in a family where her parents frequently had parties and got drunk. Furthermore, she reported that her father was a marijuana user and that her brother introduced her to smoking marijuana; Tara later wound up in a residential drug treatment program. The families of these young women appear to have provided social environments where drug and alcohol use were deemed acceptable behavior.

Other emerging adults were influenced by their families in more indirect ways. Scott, for example, drank in response to family circumstances rather than because of his family member's own substance use. Scott first started using alcohol at age 13. He recalls, "It was right after my mom died. And I always thought people would get depressed and drink. I fig- 
ured it would help and I never drank before so I . . chugged like two forties of Mickey's. . . I I was so drunk, I was puking all over the place." It is possible that Scott learned the connection between depression and alcohol use from previous family experiences. He reports that his mother and father "both drank really hard" and that his paternal grandfather drank every day. Thus, Scott was exposed to a social environment where alcohol use was a frequent occurrence and drinking may have been the way his family dealt with their problems.

The parents, siblings, and close relatives of the emerging adults in the sample were often heavy drinkers and drug users. Given this exposure, it is possible that numerous emerging adults were influenced by their family members' behavior. This may have been in the form of direct influence (i.e., some parents were actively engaged in drug use with their children) or indirect influence (i.e., having drugs in the house and having parties). Emerging adults growing up in these families were more likely to have started drinking and using drugs prior to being on the street perhaps because of the belief that this behavior is acceptable.

Another pathway into substance use was through a partner. Five respondents reported that a partner was influential in their initiation into substance use; three of these, however, credited their initiation to a partner as well as one or more of the other avenues discussed (i.e., family, friend, or the cultural context of street life). Although Shannon first began using marijuana in the 6th grade, she admits that she did not begin using hard drugs (e.g., crank, crack) until she was coerced into it by her partner when she was on the streets. She reports, "[My boyfriend] was a big druggie and I didn't want to [use drugs], but I knew that if I didn't, he'd beat the crap out of me, and [so] I did [use drugs]."

Two young women reported using drugs because of a crush they had on a young man-that is, they wanted the young men to like them and they tried to accomplish this by, in their words, "playing it cool," which included experimenting with drugs. Jolene for example, wanted to impress a young man, who was smoking marijuana, and whom she had a crush on. When he offered her a hit, she said she took it because she wanted him to like her. Stacey, a young woman previously classified as initiating marijuana and alcohol use because of her family, began using illicit drugs via her boyfriend. She reported that her boyfriend introduced her to crack. Stacey explains, "It started out with him using and blowing the smoke in my face. Then he handed me the pipe and told me to inhale so I did, and then I started smoking crack."

Numerous respondents $(n=11)$ began using drugs because of the influence of their friends and acquaintances; this was common among both males and females in the current study. Scott began using marijuana at age 15 and reports being introduced to it by his similarly aged peers. As- 
sociating with substance-using peers may make it easier for emerging adults to partake in such behavior because using drugs may be viewed as a normative activity within these circles. Additionally, noncompliance likely goes against established norms, which may lead to name calling, coercion, and possible exile from the group. Danny, for example, admits to being coerced into drinking. He explained,

I was at a party and some of my friends were drinking and they're like, "[Come on, drink]," and I was like, "I don't want to drink." Someone said, "You pussy, drink" or some shit, you know, and I'm like, "Ah, fuck" [and then I drank].

This has happened to Danny on more than one occasion. Given that street-based groups often provide safety and protection for their members (Hagan \&McCarthy, 1997) and that such protection is important for surviving on the streets, it is likely that emerging adults will continue to succumb to peer pressure surrounding alcohol and drug use if they wish to continue to associate with such groups.

Shane described a situation in which he was coerced into smoking marijuana in exchange for a place to stay. Shane's housed friend allowed him to stay with him but threatened to alert his parents (the homeowners) and thus have him thrown out if Shane did not smoke marijuana with him. He said that he has been forced to use marijuana on more than a few occasions. Shane and other emerging adults may give in to blackmail because their only alternative may be to sleep on the streets.

The final pathway into substance use for some young people was through the cultural context of the street, which includes the need to survive. Five individuals indicated that the context of the street, in combination with other agents, was responsible for their initiation; one person indicated that street life was solely responsible. Dianne, for example, reported finding it very difficult to survive on the street; she began smoking marijuana and drinking to make her situation seem more bearable. Joe, whose mother reportedly associated with "crack heads," was also living on the streets at age 15 and was using and selling drugs. He said it was street life that led to his involvement. More specifically, the cultural context of street life, which includes the daily struggles (i.e., where to go to the bathroom, where to shower, where to sleep, how to get money to eat, etc.) that homeless-emerging adults endure each day is often responsible for their initiation into substance use.

Carol's life is the epitome of how homeless-emerging adults may be initiated into drug use through the cultural context of street life - that is, although Carol initially worried about how she was going to deal with all of the daily struggles of street life, she indicated that after smoking mar- 
ijuana, she was no longer concerned about washing her clothes nor did she worry about where her next meal would come from; her only concern became getting high. According to Carol, although drug use solved some of her problems, it also created new ones; she had to discover where she was going to get the $\$ 10$ that she needed to get high every day. By placing substance use within the cultural context of having to survive on the street, it becomes clear that drug and alcohol use can become tools for coping, which is the next theme to which we now turn.

\section{Reasons for Using Alcohol and Drugs}

Almost one half of respondents $(n=18)$ reported that alcohol and drug use helped them cope with a variety of problems such as family abuse, stress, and being homeless (see Table 2). Dianne, for example, who had difficulties dealing with the emotional pain that she was experiencing as a result of being sexually abused by her adopted father, reported that smoking marijuana made her feel better because it helped to block out these experiences. In her own words,

If I smoke marijuana a couple times, you know, off and on every now and then, it just kind of makes me feel a little better and it's kind of like a security blanket for me right now. ... It's my security blanket against [my father].

Dianne thus uses marijuana as a coping strategy to help her forget about the emotional pain of early abuse. Randy also reports using marijuana as a way to cope with early abuse. Specifically, Randy detailed how he was beaten with a board by his stepfather, which resulted in bruising on most of his body. Smoking marijuana was a way for Randy to forget about the physical abuse that he had previously endured. Although smoking marijuana made Randy feel, in his own words, "normal," he does not believe in drinking alcohol as a way to cope because of the potential negative outcomes. He states,

I've heard too many people who [drink] when they are upset or stressed.

... And they become alcoholics because they start relying on it that way.

And it's not something I want to do, so even if I feel like having a beer if I'm upset, you know, I still won't.

Ironically, despite Randy's aversion to using alcohol as a coping mechanism, it appears that his own marijuana use for coping purposes is little cause for concern.

Jordan says that he smokes marijuana because it provides a calming effect. He reports, "[Marijuana] helps me think better; I can sleep better; 
I'm more productive when I'm high." Jordan has also used alcohol as a method of coping. He recalls going on a drinking binge to deal with the emotional pain of his girlfriend leaving him for someone else. Jordan explained how it was emotionally frustrating for him and how he drank for one week straight to avoid thinking about his situation.

Other emerging adults reported using drugs because of the positive sense of emotional well-being that they experience while using. Samantha, who uses drugs on a daily basis, reported, "I want [drugs] in my life 'cause that's the only way I feel like I'm happy." When asked how using drugs makes her feel, Samantha replied, "Like I'm worth something ... that I'm not depressed; I just feel happy. I don't try to focus on my problems." Similarly, Julia reports that when using drugs, "I was the easiest person to get along with in the world. I was happy, I was carefree. I didn't give a shit what was going on. I loved everybody." Given that drug use makes her feel positive, it is possible that she, like Samantha, uses drugs to cope with her past and her current situation of being homeless.

Numerous respondents reported feeling stressed out because they lacked money, food, and a place to live. According to Sara, it is a neverending chain of stressful events: "There's like a million things all happening at once and I think I've gotten to the point where I'll drink a beer and I won't think about it." Similarly, Rick reports using marijuana when he is stressed out because he gets to a breaking point where he can no longer cope. According to Rick, "[Marijuana] will calm my nerves." Danny, who also smokes marijuana to cope with life stressors, compares the effect that marijuana has on him to a hyperactivity medicine such as Ritalin. He explains,

[Marijuana] blocks out all the other bullshit going on in me. Like, you know, I'll be sitting, trying to think to myself, and you got Joe Blow over here talking all loud and [these people] over there fighting or some shit, and I'm all into their mix. But weed just makes me sit down and ... it sets my mind on something.

Similarly, Michael also reported that alcohol and marijuana were medications for the stress and depression that he was experiencing. That is, they made him feel good and they worked to relax his mind. According to Michael:

What [alcohol]would do is it would slow down my brain enough to where, you know, it was like [when I was sober], I'd be all tripping and everything, [but after drinking, I'd] be sitting back relaxing. ... Alcohol does the same thing that weed does to me, it relaxes me, relaxes my brain enough to where, you know, the depression ... the things that happen to make the depression for me, my brain don't focus on that. 
Sara, Danny, Rick, and Michael acknowledge numerous stressors that they are currently facing, and according to them, substance use is away to cope. Others also reported that they smoked marijuana for coping purposes. Kurt says that people, in general, make him feel stressed, and when this happens, he likes to be alone and "smoke a blunt" before "coming back to reality." According to Kurt, "People do so much mental and physical damage to you that it's pathetic," and smoking marijuana helps him to deal with this particular stressor. Kurt explains further,

I do smoke pot, and when [I do], I can be around people, you know, they don't really get to me. ... When I'm not high, they get on my nerves. I can't stand everything they say. It's just like, 'I want to cut your head off' ... Weed helps me cope. It helps me put up with them. It helps me be able to mediate and block them out, you know, without [them] bothering me.

Greg also has a difficult time dealing with people, and he admits that using drugs helps him create his own world and enables him not to take life so seriously. Given the numerous stressors that many of these homeless-emerging adults face on a daily basis, Greg's philosophy of not taking life so seriously is likely crucial to his well-being.

Several other emerging adults reported that drug use helped them cope and to forget about the struggles that they faced as a result of life on the street. Although Cindy discussed having health problems, she then explained how drinking alcohol and using drugs helped her to forget about them:

I didn't really worry about it. It was like, "If I don't eat, oh well, I'm getting drunk." It doesn't matter 'cause I won't be able to tell. My stomach's not going to growl loud enough for me to notice it, you know, because I'm going to be oblivious. And then as far as hygiene, oh my God, who cares? I'm high, I'm drunk, it's okay, you know?

According to Cindy, her problems associated with being on the street disappeared, at least temporarily, when she was using illicit drugs. Similarly, Carol also spoke about how marijuana helped her to cope with struggles associated with street life: "It was like, I didn't care if I wore the same clothes. I didn't care if I had nowhere to sleep. It's like, I just wanted to get high." Marijuana became a panacea for some respondents because problems associated with street life disappeared at least temporarily when these young people were high, and drugs made it easier for them to forget about their current life situations. Carol's response echoes this sentiment. She reports, "[Using drugs] makes everything funny, and you just don't think about [it]. It's really easy for me to forget about all 
my other problems because I would be laughing at something else that was going on."

Mary also used illicit drugs as a method for coping with street life, but unfortunately for her, it became habit forming, and before she knew it, she was addicted. In the following, Mary reflects on how marijuana use also affected her life:

If I was in a good mood, I would smoke [marijuana]. If I was in a bad mood, I was smoking. If I was just not in any mood, I would smoke and it didn't take any problems away. It actually added more to it, and if you get high, you start to analyze everything that was out there and you start to run things through your mind and be like "Man, if I wasn't smoking, I wouldn't be going through this." I lost two apartments due to weed. If I hadn't been smoking weed, I would have never hung around the people I hung around with and I would never did half the things I did.

After a period of time, drug use no longer provided an effective coping strategy for Mary, as was the case for some other emerging adults, but instead was associated with numerous negative outcomes as she indicated above.

In contrast to using drugs to cope with problems, a smaller group of emerging adults $(n=9)$ reported that they used substances socially (i.e., for fun or recreation and as a way to fit in). Two factors that distinguish this latter group from the former include (a) sporadic alcohol and drug use and (b) the use of substances only when socializing with friends rather than as a way to forget and cope with problems. Jennifer who used alcohol approximately every other month says that she does not drink to feel good about herself but rather drinks for the social aspect of it (i.e., getting together with friends). Denise's reasons for substance use echo those of Jennifer's; she uses drugs "just for fun," and points out that use occurs only on weekends, not on a daily basis. Similarly, Jackie says she has an occasional beer and uses marijuana, but claims that "it's all recreational." Despite the fact that many emerging adults reported using drugs as a form of coping, Jackie is adamant about not using substances for this reason. She explains,

I think that when you smoke or drink alone, that is the first sign of addiction. That is the first sign that you are smoking or drinking to cover up emotion. And I didn't do that. I refuse to do that. If I'm sad, I don't drink, I don't do pot. If I'm angry, I don't drink, I don't do pot. If I'm happy, oh hell yea, I'll drink and I'll do pot all I want because I am happy. And the minute I start regressing into another mood ... due to my own feelings or due to somebody else's actions and feelings, I'll stop because I like to maintain a level of sobriety. 
It appears that Jackie is cognizant of the fact that some emerging adults use substances as a form of coping, and obviously, she feels strongly that this is not an effective strategy for dealing with problems. Other emerging adults, although not overtly pressured into using, did so because they wanted to fit in and be part of the group. Vanessa explains, "When I was smoking [marijuana] ... I was only doing it because ... I was just trying to look normal." On the street, substance use is likely to be rewarded (i.e., acceptance into the group) and noncompliance is likely to be negatively sanctioned (e.g., name calling, exclusion from the group); therefore, because Vanessa, in her own words, was "trying to look normal," she likely felt she had to imitate and model the group's behavior to be accepted.

\section{Pathways Out of Substance Use}

The experiences of emerging adults varied widely in terms of pathways out of substance use. For approximately one third of young people $(n=12)$, it was some precipitating event (e.g., pregnancy, jail time) that made it possible for them to eventually transition out of using alcohol and drugs. Others, however, although they had good intentions, were unable to successfully make this transition $(n=4)$. Finally, there was a large group of emerging adults who had no intentions of quitting their current practice of drug use $(n=22$; see Table 2).

One common pathway out of substance use was initiated by a pregnancy; this was the case for five young women. Sandra was using marijuana on a daily basis and using crank 3 to 4 times per week for approximately 1 year until she found out she was pregnant, at which time she stopped completely. Stacey who was also using crack, stopped suddenly when she found out she was pregnant. She says, "I stopped smoking 'cause I don't want to lessen no baby's life because of what I do." Becoming pregnant was also the driving force behind Tara and Jennifer's pathway out of substance use. Finally, Carol, who was previously an avid marijuana user and dabbled in other drugs such as cocaine, had stopped using substances since giving birth to her son. She states, "Getting high is not fun anymore. I mean, I've done it a few times but it's not the same 'cause I have too much to worry about. It's like, if I get high now, the baby will start crying, [and then] how am I going to hold him if I'm high. ... It's just not the same." This quote demonstrates that Carol recognizes her responsibilities and acknowledges that she is not capable of caring for her son when she is using drugs.

Others indicated that they stopped using substances because a partner wanted them to quit or because they recognized they had a problem and were getting in trouble. Danielle, for example, indicated that she quit using drugs at age 13 because she was constantly getting into trouble (e.g., 
skipping school, running away). She eventually came to the conclusion that the consequences outweighed the benefits, and she gave up using drugs. Similarly, Debbie recognized that she had a problem with drinking, so she quit. She says,

I used to have a problem with vodka. I used to drink like a fifth every Friday and Saturday night. Every weekend, I'd just down it by myself. I was doing whatever I wanted, and then I've just kind of found out I had a problem, and I quit.

Sara, who has experimented with a number of different drugs as well as having engaged in binge drinking, says that she has given up coke for a number of reasons, stating, "I know it's bad for me, I'm on probation, and my boyfriend does not want me to do it anymore." Ryan transitioned out of using drugs because he had no choice; he was in jail for approximately 9 months prior to the interview. He does, however, have a history of using coke, marijuana, and methamphetamines. Finally, Michael, who was dealing drugs and drinking heavily, reports having had a revelation one day that was responsible for his transitioning out of drug use. He explains,

I just decided one day. ... [I had] passed out in the middle of [an intersection] ... was almost hit by four cars, [and] was not acknowledgeable of what was going on. Woke up the next morning [at the police station] going "What happened? Where am I? Why am I here?" ... That was the day when I decided. I went to the Salvation Army ... and got into the NA and AA programs.

Although these responses may suggest that the decision to transition out was based on a single episode, it is possible that their statements may be oversimplifying their decision to quit and that additional factors may also be responsible, although the respondents did not discuss them during the interview.

Though these emerging adults have been successful at transitioning out of drug use, the risk of being pulled back into the drug environment still exists for some of them. John, for example, was living at the $Y$ and was experiencing peer pressure from some of the other young people who resided there. Although John had stopped using illicit drugs, he indicated that abstinence was becoming increasingly difficult for him because of his interactions with drug-using individuals, given his living situation. John explains,

People want me to go where they go, [use] drugs with them, stuff like I can't do because I'm working. I want to get out of here ... I'm going to be getting help you know, and I don't want to [use drugs]. ... They just can't understand that, but I want to make my life better. And they make it hard for me. 
There was a small group of emerging adults who were trying to quit using drugs but had not been successful. Samantha was definitely concerned about where her future was headed. She said, "My life is going nowhere. I don't feel anything in the future. I don't see myself anywhere doing anything right now." She reported that she does not hope but rather lives day by day. Her dream for the future was "to be clean and have a job." Given her current drug and mental health problems, it is unlikely that Samantha will be able to transition out of drug use without the help of intervention programs.

Rick also wanted to transition out but found it hard given the group of friends with whom he associated. Rick reports,

I don't like the fact that I do [drugs]. I don't like the fact that they're around me. I'd like to get rid of them, but at this particular point in time, with the friends I have, [drugs are] going to be there.

Given that Rick was homeless, his choice of friends was likely limited and until he is able to leave the streets, his associations with drug-using peers and his current drug use is likely to continue regardless of his intentions to quit. Similarly, despite her efforts, Mary also found it difficult to quit given her associations with a group of drug-using peers. Emerging adults who affiliate with drug-using peers are likely to adopt similar lifestyles and continue to use so that they can remain part of the group. Finally, Candy quit using drugs and alcohol for 3 years until she had a relapse one night while at a party. She reported, "I went to a party 'cause I needed time away from [my son] ... I drank and I drank and I drank and I drank. And I got messed up." Candy indicated that she turned to drinking once again because the more she drank, the less she worried about her problems; drinking, for her, remained a way to cope when other options were unavailable.

The final group of emerging adults, who did not wish to quit, included two extremes: (a) those that felt that they did not have a problem with drugs and used them only sporadically $(n=11)$ and $(b)$ those who were avid users $(n=11)$. Among those in the first group, young people typically reported that they smoked marijuana or drank alcohol every other week or so. For them, substance use was not used to cope with stress or problems associated with street life but rather was engaged in for fun or as a way to socialize. Jackie, for example, reports,

If I'm gonna drink, I'm going to take, like, a six pack of beer to my dad's house so me and my dad can have a few beers together over a nice steak or something. ... I've never really been one to get drunk; I just like the flavor of beer or wine coolers. 
Those in the second group of emerging adults, however, were heavily involved in substance use and did not discuss transitioning out. When asked how drugs made him feel, Brian replied, "[Like I am] at home, that's my life, that's my profession. It's what I've done my whole life ..." Brian reports using alcohol, marijuana, and hard drugs on a weekly basis, and it is clear from the above quote that he has no intention of quitting in the near future. Similarly, Jordan offers his thoughts on marijuana: "I smoke pot. I don't care what anybody thinks. I think it should be legalized. ... Everybody should smoke pot." Similarly, Danny says that the only negative aspect of his 4 or 5 gram a day marijuana habit is that it is illegal. He states that he does not intend to stop using marijuana but, rather, is "waiting on the government to make it legal." Unlike their sporadically using peers, these avid users were more dependent on drugs and had no intentions of quitting; drugs provided them with an escape from reality. Additionally, some emerging adults could not afford to quit given the financial benefits that selling drugs provided them with.

\section{Discussion}

Consistent with previous work (Bailey et al., 1998; Baron, 1999; Kral et al., 1997; MacLean et al., 1999; Martinez et al., 1998; Warheit \& Biafora, 1991), the current study found high rates of alcohol and drug use among the respondents - that is, $85 \%$ of respondents have used or are currently using marijuana; approximately $53 \%$ have used or are currently using illicit drugs; and $75 \%$ are heavy substance users. Although national statistics find that emerging adults have the highest rates of substance use in the general population (21\% for alcohol and illicit drugs and $15 \%$ for heavy alcohol use; Substance Abuse and Mental Health Services Administration, 2003), the percentages among homeless-emerging adults are much higher than this.

Many of the emerging adults listed a friend or acquaintance (typically other street people) or a family member as being responsible for introducing them to alcohol and drugs. These findings are similar to those of Kipke and colleagues (1996). Consistent with the work of Baron (1999), homeless-emerging adults often have family histories that promote substance use. This is apparent by the large number of respondents who indicated that a close family member (usually a mother or father) had a substance abuse problem $(n=37 ; 93 \%)$ and by the number of respondents who said that their mother or father had experienced legal sanctions, often because of selling drugs $(n=13 ; 33 \%)$. These figures are very similar to those found by Ginzler and colleagues (2003) who found that an inordinate number of parents of homeless young people had substance 
misuse related problems. Additionally, although beyond the scope of this article, future research may also wish to examine the effect of genetic factors on substance use (Young, Lawford, \& Noble, 2004) and on age of onset of alcohol dependence (Liu et al., 2004).

Reasons for using substances varied, but the majority of respondents reported that alcohol and drugs were used as a way to cope with experiences of early child maltreatment, depression, and with the stressors of street life. Many reported that using drugs made them feel happy and carefree and helped them to forget (at least temporarily) their current situation. As some emerging adults reported, when they were high, they did not care about where their next meal was coming from, where they were going to sleep, and what was happening to them. This finding is consistent with the work of Kidd and Kral (2002) who also found alcohol and drugs to be a way to cope with the stress of street life. Although some researchers have also found that homeless young people may use methamphetamines to stay awake for extended periods of time, thus lessening their chances of being victimized (Ayerst, 1999; Ginzler et al., 2003), the current study revealed only two emerging adults who reported using illicit drugs for this purpose. Other respondents in the current study reported using drugs for social reasons (i.e., for fun and to fit in with other people), and finally, about one quarter of the respondents reported using substances for both coping and social reasons.

For many emerging adults, the pathway out of substance use was aided by some precipitating event, such as a pregnancy. Other individuals had tried to desist from using substances but were unsuccessful in their attempts. Finally, there was a larger group of youth who had no intentions of quitting because they felt either (a) they did not have a problem with alcohol and drugs and used them only for social reasons or (b) although they were heavy users, they did not view their substance use as a problem. The individuals that made up the latter group were typically those who were more dependent on drugs for the escape from reality that the drugs provided and for the financial benefits that selling drugs provided them with.

There are some limitations that should be noted. First, many of the questions were retrospective in nature (e.g., history of alcohol and drug use), and thus, some respondents may have been unable to remember all of the specifics. Conversely, because of the qualitative nature of the interview, individuals had time to reflect, and many gave vivid recollections of their first time using alcohol and illicit drugs. A second limitation is that both authors were involved in both rounds of the coding process, and it is possible that the second round was influenced by the first round. Third, it was not possible to randomly sample the 40 participants from the larger study. Fourth, because the respondents are subject to not only 
the instability inherent in emerging adulthood but also to the added unpredictability of street life, their situations are highly variable and precarious. The substance-use patterns of homeless-emerging adults, similar to their living situations and personal relationships, are likely to change constantly, sometimes on a daily basis, and it is difficult to identify exact usage rates at any given time. Cindy, for example, was using crack on a daily basis until very recently when she was put into a residential treatment program. Candy, conversely, had an alcohol abuse problem earlier in life but had been sober for 3 years when she had a relapse prior to the interview. It is difficult to classify either of these young women as users or nonusers and even more difficult to further specify them as daily, weekly, or monthly users. Additionally, because it is impossible to know what the future holds for these women and the respondents like them, classifications of substance users are broad and thus should be examined developmentally rather than at one point in time. Finally, because of the difficulty in obtaining a random sample of homeless people, the current study is not meant to be representative of all homeless people but rather is meant to give a more in-depth understanding of some of the issues surrounding substance use among a select group of homeless-emerging adults in the Midwest.

Despite these limitations, our findings provide important information about the nature of substance use among homeless-emerging adults, which has implications for intervention and prevention. Emerging adulthood may be a particularly difficult period for homeless people because they often exceed the age requirement for youth shelters and many opt not to use adult homeless shelters because such places are viewed as unsafe. As such, many emerging adults may not receive the referrals and treatment services that they need. Substance-use problems that are left untreated may lead to chemical dependency and long-term homelessness. In addition, the heavy use of alcohol and drugs is associated with risky sexual behavior (Tyler, Whitbeck, Hoyt, \& Yoder, 2000) and victimization (Hoyt, Ryan, \& Cauce, 1999; Tyler et al., 2004). Finally, substance use may further destabilize the lives of homeless-emerging adults making it even more difficult for them to find employment, maintain stable relationships, and transition off of the streets.

From a developmental perspective, current substance users who began using alcohol and drugs at an early age could be termed life-course persistent (Moffitt, 1993) because of (a) the early timing of their initiation into substance use and (b) their duration of use that covers different life stages. This group is likely to be at greater risk for developing chemical dependency problems, which in turn, may lead to long-term homelessness. In contrast, other respondents could be termed what Moffitt (1993) calls adolescence-limited or life-course limited because (a) they did not initiate sub- 
stance use until much later ages and (b) because their involvement with substance use is likely associated with street life and their participation is expected to be short term - that is, once they find housing and leave the streets, their substance use is more likely to subside. Because of the dearth of research on this group, however, we know nothing about the characteristics that discriminate between these precursors and outcomes.

Furthermore, much less is known about what eventually happens to homeless-emerging adults. Do they find housing, return to school, or find regular employment? Although some respondents may have been on their own since their adolescent years, others are undoubtedly new to street life. Conversely, although some may remain on the streets into middle adulthood, others are likely to find their way out. It is crucial for researchers to focus on this specific age group so that we are better able to understand the behavior of homeless-emerging adults because it is possible that they are a distinct population, one that differs from both homeless adolescents and homeless adults.

In summary, friends and acquaintances as well as family members were important for first introducing the current sample of homelessemerging adults to alcohol and drugs. Substance use was a method of coping with previous and current situations among participants; using drugs made them feel happy and carefree. Although many of these emerging adults had no intention of quitting, there were some, however, who were able to transition out because of some precipitating event, whereas attempts by others were unsuccessful. Given the context of street life, which often includes being exposed to and associating with substance users, there are no guarantees that these emerging adults will remain sober or drug free. Overall, homeless-emerging adults are in a critical transition period, a time when work patterns are established and marital relationships are formed. Those who are unable to make a successful transition to young adulthood may continue on this life-course persistent trajectory whereby long-term repercussions may include chemical dependency and chronic homelessness. 


\section{Appendix A}

\section{Becoming Homeless}

Young people were asked the age at which they ran away or left home for the first time as well as the number of different times. If respondents ran more than one time they were asked about the different ages at each run. Additionally, young people were asked about why they left home and where they went.

\section{Child Maltreatment}

Respondents were asked if they had ever been physically abused and sexually abused while living at home. Young people who answered yes were then asked to tell the interviewer about what happened if no information was volunteered. Almost all young people who were abused, however, volunteered their stories without being prompted. Respondents were also asked about how often the abuse occurred and who the perpetrators were.

\section{Family Histories}

Young people were asked if any family members used alcohol and drugs and whether they were involved in criminal activity. For those respondents who answered yes, interviewers then asked them who was involved (i.e., specific family member(s)); what type of substances they used; how often; and the type of criminal activity that family members were involved in.

\section{Respondents Substance Use}

Participants were asked if they had ever used alcohol and drugs. Once again, young people who answered yes typically volunteered information about their usage. If not, interviewers probed for more details. For example, respondents were asked if currently using; how often they use substances; in what situations do they use substances; how does using drugs or alcohol make them feel; who do they engage in these behaviors with; if they have ever been forced to use substances; and when and why they began using 


\section{Appendix B}

Emerging Adults Were Coded as ...

\section{Pathways into substance use}

Having been initiated into substance use by family

Having been initiated into substance use by a partner or partners

Having been initiated into substance use by friends or acquaintances

Having been initiated into substance use through the cultural context of the streets

\section{Reasons for using substances}

Using substances for coping

Using substances socially and for recreation

\section{Pathways out of substance use}

Transitioning out of substance use because of a precipitating event

Having been unsuccessful in transitioning out of substance use

Being heavy users and having no intention of transitioning out of substance use

Being occasional and minor users and having no intention of transitioning out of substance use
If They Said Something Like... .

A family member showed them how to use, used substances with them or in front of them, a caretaker allowed them to use substances in the house, etc.

Their partner forced them to use, they didn't use until they began dating this partner, they were trying to impress a potential partner, etc.

They experienced peer pressure to use, their friends or acquaintances showed them how to use and provided them with drugs the first time they used, etc.

They began using substances because it was part of street life, they started using when they started running away, they sought out a way to deal with street life and found drugs useful, etc.

They couldn't feel happy unless they were using, they used substances to block out bad memories, they used substances to numb themselves against the difficulties of living on the streets, etc.

They used substances for something to do, they used because it was fun, etc.

They stopped using substances because they got pregnant and gave birth, went to treatment or jail, had a revelation and realized that they needed to quit, etc.

They wanted to quit using substances but they were unable to, they had been to treatment but had relapsed, etc.

They used substances very frequently and liked it, no mention was made of a desire to quit, etc.

They spoke of very occasional and sporadic use of alcohol or marijuana, but did not appear to have a substance abuse problem and did not mention any desire to quit 


\section{References}

Arnett, J. J. (in press). The developmental context of substance use in emerging adulthood. Journal of Drug Issues.

Arnett, J. J. (2000). Emerging adulthood: A theory of development from the late teens through the twenties. American Psychologist, 55, 469-480.

Arnett, J. J. (2004). Emerging adulthood: The winding road from the late teens through the twenties. New York: Oxford University Press.

Ayerst, S. L. (1999). Depression and stress in street youth. Adolescence, 34, 567-575.

Bailey, S. L., Camlin, C. S., \& Ennett, S. T. (1998). Substance use and risky sexual behavior among homeless and runaway youth. Journal of Adolescent Health, 23, 378-388.

Baron, S. W. (1999). Street youths and substance use: The role of background, street lifestyle, and economic factors. Youth and Society, 31, 3-26.

Carey, J. W., Morgan, M., \& Oxtoby, M. J. (1996). Intercoder agreement in analysis of responses to open-ended interview questions: Examples from tuberculosis research. Cultural Anthropology Methods, 8, 1-5.

Charmaz, K. (1995). Grounded theory. In J. A. Smith, R. Harré, \& L. V. Langenhove (Eds.), Rethinking methods in psychology (pp. 27-49). Thousand Oaks, CA: Sage.

Fors, S. W., \& Rojek, D. G. (1991). A comparison of drug involvement between runaways and school youth. Journal of Drug Education, 21, 13-25.

Ginzler, J. A., Cochran, B. N., Domenech-Rodriguez, M., Cauce, A. M., \& Whitbeck, L. B. (2003). Sequential progression of substance use among homeless youth: An empirical investigation of the gateway theory. Substance Use and Misuse, 38, 725-758.

Hagan, J., \& McCarthy, B. (1997). Mean streets: Youth crime and homelessness. New York: Cambridge University Press.

Hoyt, D. R., Ryan, K. D., \& Cauce, A. M. (1999). Personal victimization in a high-risk environment: Homeless and runaway adolescents. Journal of Research in Crime $\mathcal{E}$ Delinquency, 36, 371-392.

Janus, M., McCormack, A., Burgess, A. W., \& Hartman, C. (1987). Adolescent runaways: Causes and consequences. Lexington, MA: Lexington.

Kidd, S. A., \& Kral, M. J. (2002). Suicide and prostitution among street youth: A qualitative analysis. Adolescence, 37, 411-430.

Kipke, M. D., Montgomery, S. B., Simon, T. R., Unger, J. B., \& Johnson, C. J. (1997). Homeless youth: Drug use patterns and HIV risk profiles according to peer group affiliation. AIDS and Behavior, 1, 247-259.

Kipke, M. D., Unger, J. B., Palmer, R. F., \& Edgington, R. (1996). Drug use, needle sharing, and HIV risk among injection drug-using street youth. Substance Use and Misuse, 31, 1167-1187.

Kral, A. H., Molnar, B. E., Booth, R. E., \& Watters, J. K. (1997). Prevalence of sexual risk behavior and substance use among runaway and homeless adolescents in San Francisco, Denver and New York City. International Journal of STD and AIDS, 8, 109-117.

Liu, I., Blacker, D. L., Xu, R., Fitzmaurice, G., Lyone, M. J., \& Tsuang, M. T. (2004). Genetic and environmental contributions to the development of alcohol dependence in male twins. Archives of General Psychiatry, 61, 897-903. 
MacLean, M. G., Paradise, M. J., \& Cauce, A. M. (1999). Substance use and psychological adjustment in homeless adolescents: A test of three models. American Journal of Community Psychology, 27, 405-427.

Martinez, T. E., Gleghorn, A., Marx, R., Clements, K., Boman, M., \& Katz, M. H. (1998). Psychosocial histories, social environment, and HIV risk behaviors of injection and noninjection drug using homeless youths. Journal of Psychoactive Drugs, 30, 1-10.

Moffitt, T. E. (1993). Adolescence-limited and life-course-persistent antisocial behavior: A developmental taxonomy. Psychological Review, 100, 674-701.

Rosenthal, D., Moore, S., \& Buzwell, S. (1994). Homeless youths: Sexual and drug related behaviour, sexual beliefs and HIV/AIDS risk. AIDS Care, 6, 83-94.

Substance Abuse and Mental Health Services Administration. (2003). Results from the 2002 National Survey on Drug Use and Health: National findings. NHSDA Series H-22, DHHS Publication No. SMA 03-3836. Rockville, MD: Office of Applied Studies.

Tyler, K. A. (in press). A qualitative study of early family histories and transitions of homeless youth. Journal of Interpersonal Violence.

Tyler, K. A., \& Cauce, A. M. (2002). Perpetrators of early physical and sexual abuse among homeless and runaway adolescents. Child Abuse $\mathcal{E}$ Neglect, 26, 1261-1274.

Tyler, K. A., Whitbeck, L. B., Hoyt, D. R., \& Cauce, A. M. (2004). Risk factors for sexual victimization among male and female homeless and runaway youth. Journal of Interpersonal Violence, 19, 503-520.

Tyler, K. A., Whitbeck, L. B., Hoyt, D. R., \& Yoder, K. A. (2000). Predictors of self-reported sexually transmitted diseases among homeless and runaway adolescents. Journal of Sex Research, 37, 369-377.

Warheit, G. J., \& Biafora, F. (1991). Mental health and substance abuse patterns among a sample of homeless post-adolescents. International Journal of Adolescence and Youth, 3, 9-27.

Whitbeck, L. B., \& Hoyt, D. R. (1999). Nowhere to grow: Homeless and runaway adolescents and their families. New York: Aldine de Gruyter.

Young, R., Lawford, B. R., \& Noble, E. P. (2004). Advances in molecular genetics and the prevention and treatment of substance misuse: Implications of association studies of the A-sub-1 allele of the D-sub-2 dopamine receptor gene. Addictive Behaviors, 29, 1275-1294.

$\circ 0000000$

Kimberly A. Tyler, Ph.D., is an associate professor in the Department of Sociology at the University of Nebraska-Lincoln. Her research interests include homelessness, child abuse and neglect, victimization, and high-risk behaviors among adolescents and youth.

Katherine A. Johnson, M.A., is a doctoral student at the University of NebraskaLincoln. Her research interests include the study of crime, gender, and high-risk youth using both qualitative and quantitative methodology. 